\title{
Declining carbohydrate solubilization with increasing solids loading during fermentation of cellulosic feedstocks by Clostridium thermocellum: documentation and diagnostic tests
}

Matthew R. Kubis ${ }^{1,2}$, Evert K. Holwerda ${ }^{1,2^{*}}$ (1) and Lee R. Lynd ${ }^{1,2}$

\begin{abstract}
Background: For economically viable 2nd generation biofuels, processing of high solid lignocellulosic substrate concentrations is a necessity. The cellulolytic thermophilic anaerobe Clostridium thermocellum is one of the most effective biocatalysts for solubilization of carbohydrate harbored in lignocellulose. This study aims to document the solubilization performance of Clostridium thermocellum at increasing solids concentrations for two lignocellulosic feedstocks, corn stover and switchgrass, and explore potential effectors of solubilization performance.

Results: Monocultures of Clostridium thermocellum demonstrated high levels of carbohydrate solubilization for both unpretreated corn stover and switchgrass. However, fractional carbohydrate solubilization decreases with increasing solid loadings. Fermentation of model insoluble substrate (cellulose) in the presence of high solids lignocellulosic spent broth is temporarily affected but not model soluble substrate (cellobiose) fermentations. Mid-fermentation addition of cells (C. thermocellum) or model substrates did not significantly enhance overall corn stover solubilization loaded at $80 \mathrm{~g} / \mathrm{L}$, however cultures utilized the model substrates in the presence of high concentrations of corn stover. An increase in corn stover solubilization was observed when water was added, effectively diluting the solids concentration mid-fermentation. Introduction of a hemicellulose-utilizing coculture partner, Thermoanaerobacterium thermosaccharolyticum, increased the fractional carbohydrate solubilization at both high and low solid loadings. Residual solubilized carbohydrates diminished significantly in the presence of T. thermosaccharolyticum compared to monocultures of $C$. thermocellum, yet a small fraction of solubilized oligosaccharides of both $C_{5}$ and $C_{6}$ sugars remained unutilized.
\end{abstract}

Conclusion: Diminishing fractional carbohydrate solubilization with increasing substrate loading was observed for C. thermocellum-mediated solubilization and fermentation of unpretreated lignocellulose feedstocks. Results of experiments involving spent broth addition do not support a major role for inhibitors present in the liquid phase. Mid-fermentation addition experiments confirm that C. thermocellum and its enzymes remain capable of converting model substrates during the middle of high solids lignocellulose fermentation. An increase in fractional carbohydrate

*Correspondence: evert.k.holwerda@dartmouth.edu

1 Thayer School of Engineering, Dartmouth College, 14 Engineering Drive, Hanover, NH 03755, USA

Full list of author information is available at the end of the article permits use, sharing, adaptation, distribution and reproduction in any medium or format, as long as you give appropriate credit to the original author(s) and the source, provide a link to the Creative Commons licence, and indicate if changes were made. The images or other third party material in this article are included in the article's Creative Commons licence, unless indicated otherwise in a credit line to the material. If material is not included in the article's Creative Commons licence and your intended use is not permitted by statutory regulation or exceeds the permitted use, you will need to obtain permission directly from the copyright holder. To view a copy of this licence, visit http://creativecommons.org/licenses/by/4.0/. The Creative Commons Public Domain Dedication waiver (http://creativeco mmons.org/publicdomain/zero/1.0/) applies to the data made available in this article, unless otherwise stated in a credit line to the data. 
solubilization was made possible by (1) mid-fermentation solid loading dilutions and (2) coculturing C. thermocellum with $T$. thermosaccharolyticum, which ferments solubilized hemicellulose. Incomplete utilization of solubilized carbohydrates suggests that a small fraction of the carbohydrates is unaffected by the extracellular carbohydrate-active enzymes present in the culture.

Keywords: Corn stover, Switchgrass, High solid loading, Biomass deconstruction, Lignocellulose, Cellulose, Hemicellulose, Biofuels, Clostridium thermocellum, Thermoanaerobacterium thermosaccharolyticum, Coculture

\section{Background}

Conversion of lignocellulose feedstocks has attracted global interest as a sustainable source of transportation fuels. Biologically mediated events in lignocellulose conversion include production of carbohydrate-active enzymes (CAZymes), enzymatically mediated carbohydrate solubilization, and fermentation of soluble sugars [1]. Plants have evolved to be resistant to biological attack, and overcoming this recalcitrance is responsible for the high cost of current conversion technology [2]. The most widely studied strategy for solubilizing the carbohydrate fraction of cellulosic biomass involves thermochemical pretreatment and added enzymes produced by aerobic fungi [3-5]. Alternatively, some thermophilic anaerobes are naturally capable of producing cellulases and other CAZymes and then fermenting the solubilized carbohydrates to a desired product in a one-step approach called consolidated bioprocessing (CBP) [6]. Mechanical disruption during fermentation (cotreatment) has also been proposed as an alternative to thermochemical pretreatment to augment biologically mediated deconstruction (C-CBP), but is not the focus of this study [7-9].

Clostridium thermocellum (Ruminiclostridium thermocellum, Hungateiclostridium thermocellum, Acetivibrio thermocellus), a cellulolytic and thermophilic anaerobic bacterium, is the most efficient microorganism at lignocellulose solubilization known $[7,10]$, and is thus a promising candidate for CBP. Although the biomass deconstruction apparatus of $C$. thermocellum equally solubilizes pentose-rich hemicellulose as well as cellulose [7], wild-type strains do not ferment pentose sugars [1113]. As a result, xylo-oligomers accumulate when lignocellulose is fermented by $C$. thermocellum monocultures. Pentose sugars and oligomers originating from hemicellulose have a deleterious effect on lignocellulose deconstruction by fungal cellulase preparations [14-17]. There have been reports of possible effects of soluble hemicellulose on cultures of $C$. thermocellum and cell-free cellulase preparations on switchgrass $[18,19]$ and corn fiber [20].

In addition to potentially affecting cellulolytic activity, failure to utilize $C_{5}$ sugars decreases the product yield per unit biomass. To avoid these undesired effects, defined cocultures of $C$. thermocellum with a compatible hemicellulose-fermenting strain have been studied, and identifying synergistic coculture partners is important in the context of biofuel production by CBP [21]. On both microcrystalline cellulose and lignocellulose, $\mathrm{Ng}$ et al. reported that cocultures with the hemicellulose-utilizing Clostridium thermohydrosulfuricum (renamed as Thermoanaerobacter thermohydrosulfuricus) enhanced substrate consumption and ethanol yield [22]. Saddler and Chan had similar observations for C. thermocellum NRCC 2688 cocultured with Clostridium thermosaccharolyticum on pretreated wheat straw [23]. Coculture studies with Thermoanaerobacterium spp. on microcrystalline cellulose demonstrated increased product formation on crystalline cellulose in comparison to $C$. thermocellum monocultures [24-26]. Recently, Froese et al. (2018) reported $2 \mathrm{~g} / \mathrm{L}$ wheat straw cocultures with either Ruminiclostridium stercorarium or Thermoanaerobacter thermohydrosulfuricus improved carbohydrate solubilization by $30 \%$ relative to the monoculture as determined by measuring end products and soluble oligosaccharides [27]. Beri et al. showed cocultures with hemicellulose-utilizing Herbinix spp. and Thermoanaerobacterium thermosaccharolyticum on $40 \mathrm{~g} / \mathrm{L}$ corn fiber resulted in a 1.39 -fold increase (67\% to $93 \%$ ) in overall solubilization relative to the monoculture. In another study, Beri et al. described an inhibitory effect relating to a hemicellulose component of corn fiber, glucuronoarabinoxylan (GAX) [20] Supplementation of enzymes capable of disrupting the GAX-linkages alleviated inhibition and improved carbohydrate solubilization from 33 to $63 \%$ for $40 \mathrm{~g} / \mathrm{L}$ corn fiber solids loading [28].

High loadings of lignocellulosic feedstocks are required for industrial feasibility in order to avoid high costs for product recovery (e.g., steam for distillation) as well as high capital costs for bioreactors [2, 3]. For lignocellulose solubilization mediated by fungal cellulase preparations, a decrease in solubilization has been observed with increasing solid loadings [29-33]. In these systems, mass transfer and free water limitations arise as solid loadings approach $15-20 \%$ dry matter [30,33], yet several other causative factors have also been reported including, but not limited to, the presence and/or accumulation of ethanol [34,35], glucose [34, 36], cellobiose [34, 36], xylan [14, 37-40], xylose [15], xylo-oligomers [16, 17, 38], 
lignin $[35,41]$, and inhibitors related to thermochemical pretreatment [35, 42]. For mixed anaerobic consortia cultivated during anaerobic digestion (AD), it has been observed that no significant differences in the specific methane yield occur between 1 and 15\% total solids with a decrease eventually observed at $20-30 \%$ total solids [43-48]. In these studies, mass transfer limitations due to lack of free water and/or organic overfeeding have been cited as possible explanations $[44,45]$.

For defined cultures of thermophilic anaerobes aimed at lignocellulose solubilization, most studies have targeted documenting and understanding capability at solids loadings $\leq 20 \mathrm{~g} / \mathrm{L}$. At carbohydrate loadings up to $120 \mathrm{~g} / \mathrm{L}$, C. thermocellum cultures solubilize $80-93 \%$ of the cellulose present in Avicel ${ }^{\circledR}$ PH105, a model microcrystalline cellulose substrate containing negligible amounts of both lignin and hemicellulose [49-51]. However, declining solubilization with increasing loading has been observed for such cultures when fermenting unpretreated lignocellulose. Verbeke et al. [52] observed a 1.72-fold decline in solubilization extent between 50 and $10 \mathrm{~g} / \mathrm{L}$ on mid-season switchgrass that could not be solely explained by either recalcitrance or inhibition by fermentation products [52], and Shao et al. [19] also reported diminishing solubilization at increasing loadings of midseason switchgrass [19]. Both authors described a deleterious effect to lignocellulose deconstruction in the presence of $\mathrm{C}_{5}$ sugars, either in monomeric or oligomeric forms [18]. Similarly for corn fiber, Beri et al. observed declining solubilization (90-67\%) between 20 and $40 \mathrm{~g} / \mathrm{L}$ which was largely overcome by coculturing $C$. thermocellum with a hemicellulose-utilizing thermophile [20].
Caldicellulosiruptor bescii, a hyperthermophilic, cellulolytic anaerobe [53], experiences a 1.8-fold decline in carbohydrate solubilization between 5 and $50 \mathrm{~g} / \mathrm{L}$ switchgrass loadings, and the authors describe overcoming this decline by slowly purging the bioreactor liquid with substrate-free medium [54].

Here we extend the work of Verbeke, Shao and Beri et al. by documenting solubilization as a function of solids concentration by $C$. thermocellum for corn stover and senescent switchgrass with and without $T$. thermosaccharolyticum, and present experiments aimed at evaluating potential causal mechanisms.

\section{Results}

Fermentation of $C$. thermocellum with increasing solids loading

We aimed to document the impact of solids loading on fractional carbohydrate solubilization (FCS) of corn stover and senescent switchgrass in batch, $\mathrm{pH}$-controlled monocultures of Clostridium thermocellum DSM1313 incubated for 7 days at $55{ }^{\circ} \mathrm{C}$. Both of these substrates were milled to $0.5 \mathrm{~mm}$ particle size and underwent no pretreatment other than autoclaving. FCS decreases roughly linearly as the initial substrate loading is increased from 20 to $80 \mathrm{~g} / \mathrm{L}$ (Fig. 1A). Total gas production (accumulative $\mathrm{CO}_{2}$ and $\mathrm{H}_{2}$ ) increased with increasing substrate loading and indicated that fermentative activity stopped at about $100-120 \mathrm{~h}$ for the highest solid loadings and around $50 \mathrm{~h}$ for the lowest solid loadings (Fig. 1B).

As may be observed from Fig. 1, FCS decreased by similar absolute amounts for corn stover $(0.139=0.695$
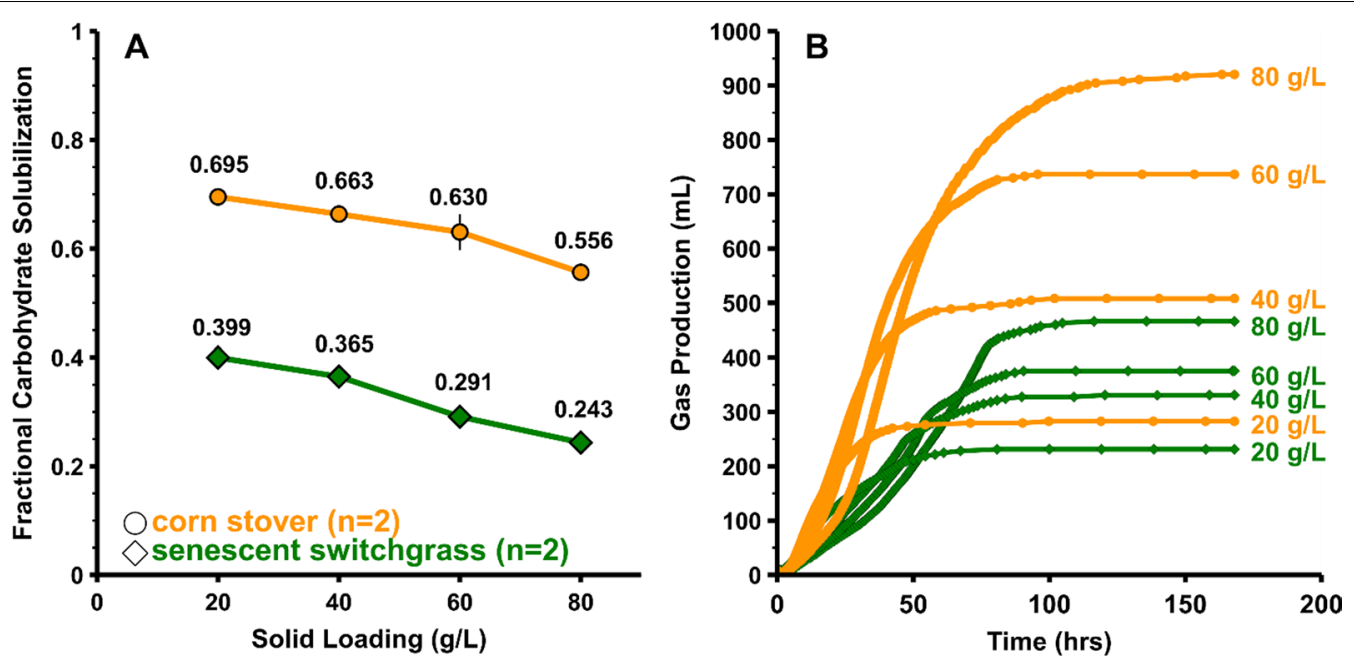

Fig. 1 Fermentation of corn stover and senescent switchgrass by monocultures of Clostridium thermocellum at various solid loadings ( $n=2$ ). A Fractional carbohydrate solubilization with error bars representing 1 standard deviation shown $(n=2)$. B Representative total gas production (cumulative $\mathrm{CO}_{2}$ and $\mathrm{H}_{2}$ ) for one of the duplicate reactors 
- 0.556$)$ and for senescent switchgrass $(0.156=0.399-$ 0.243 ), corresponding to a $20 \%$ decrease for corn stover and a $39 \%$ decrease for switchgrass. FCS at each solids loading was higher for corn stover than for switchgrass by a factor of approximately two. The total fraction of carbohydrate per solids was different for corn stover (0.676) and switchgrass (0.725), therefore the carbohydrate loading at equal solid loadings varied slightly for the two feedstocks.

With increasing solid loadings, final concentrations of fermentation products (ethanol, acetate, formate, and lactate shown in Fig. 2, panels $\mathrm{A}$ and $\mathrm{C}$ ) increased. Note that acetate can originate as a product of fermentation or a product of the solubilization process as it is present in the feedstock as acetyl bonds. According to estimates determined by Kumar et al. and Wyman et al., the acetyl content of corn stover and switchgrass is $2.51 \%$ and $3.60 \%$, respectively $[55,56]$. Based on carbohydrate solubilization, the fraction of acetate that is the result of fermentation would then range between $73.9-78.6 \%$ and $74.4-80.1 \%$ for corn stover and switchgrass, respectively (Additional file 1: Table S10).

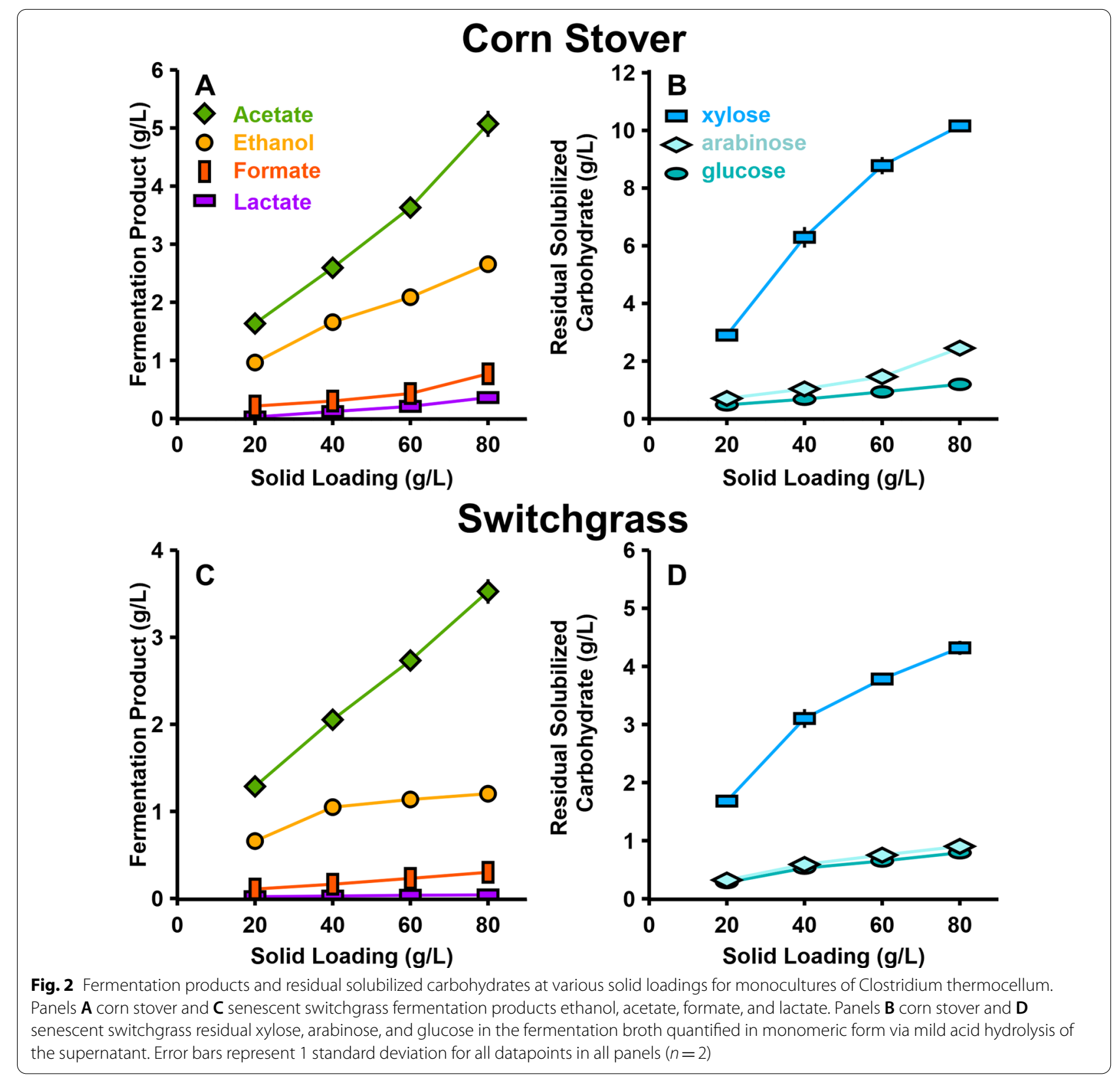


Molar ratios of the various fermentative products did not significantly change as solid loadings increased, with the exception of decreasing ethanol production in switchgrass fermentations (Additional file 1: Table S2).

Solubilized and unutilized carbohydrates exist as a mixture of complex oligomers in fermentation broth [28], but were measured in monomeric form after a mild acid hydrolysis step (see Methods), and residual solubilized carbohydrates increased with solid loadings (Fig. 2, panels B and D). While C. thermocellum strictly utilizes $C_{6}$ carbon sugars in the form of dimers and homo-oligomers of glucose linked by $\beta$-glycosidic bonds [57], a small fraction of the residual unutilized soluble carbohydrates appears to contain glucose. The other sugars present in the unutilized solubilized carbohydrates were xylose and arabinose, which is consistent with the inability of wild-type $C$. thermocellum to utilize $\mathrm{C}_{5}$ sugars $[11,12]$.

\section{Testing spent broth for inhibitory effects}

Spent fermentation broth from the aforementioned 80 (high) and 20 (low) g/L fermentations was collected and examined for inhibitory effects in subsequent bottle fermentations with fresh media and fresh substrate. The spent broth was centrifuged and filtered at $0.2 \mu \mathrm{m}$ to remove cells and any remaining solids. Additional filtered spent broth was generated by fermenting $12.1 \mathrm{~g} / \mathrm{L}$ cellobiose or cellulose, corresponding to the amount of glucan solubilized in an $80 \mathrm{~g} / \mathrm{L}$ corn stover fermentation. The spent media then was aseptically added in $75 \%$ volumetric amounts $(15-\mathrm{ml})$ to a $20-\mathrm{mL}$ final volume serum bottle containing fresh media and either $5 \mathrm{~g} / \mathrm{L}$ microcrystalline cellulose (Avicel PH105) or $5 \mathrm{~g} / \mathrm{L}$ cellobiose (concentration prior to inoculation) as carbon and energy source (Fig. 3). Bottles with $75 \% \mathrm{v} / \mathrm{v}$ water instead of spent broth served as internal controls. To see if the spent broth had any transient or permanent effects on the solubilization and utilization processes, the net product formation was measured every $24 \mathrm{~h}$ for a total of 5 days (product concentration measured minus product concentration present at start of incubation). As shown in Fig. 3, net product formation at the end of bottle incubation was comparable for those with and without spent broth, suggesting the spent broth has limited effects towards the final utilization of model substrates for C. thermocellum. However, there was a temporary lag in product formation of up to $50-75 \mathrm{~h}$ in the bottles containing cellulose and spent broth from high solid loadings $(80 \mathrm{~g} / \mathrm{L})$. This delay was not observed for fermentation with cellobiose or at low solid loadings ( $20 \mathrm{~g} / \mathrm{L})$.

\section{Addition of cells and substrates during fermentation of $80 \mathrm{~g} / \mathrm{L}$ corn stover}

In order to gain diagnostic insights into declining solubilization with increasing substrate loading, model substrates and cells were added $48 \mathrm{~h}$ after inoculating duplicate $300-\mathrm{ml}$ batch cultures of $C$. thermocellum in $\mathrm{pH}$-controlled bioreactors with an initial corn stover loading of $80 \mathrm{~g} / \mathrm{L}$. Corn stover was chosen as it gave higher solubilization results compared to switchgrass in the previous experiment. Several additions were made including $60-\mathrm{ml}$ solutions of microcrystalline cellulose (Avicel PH105), cellobiose, cellobiose-grown cells concentrated by centrifugation, and water which served as an internal control. Additions of cellobiose and cellulose increased the total carbohydrate loading by $32 \%$ (from 54.1 to $71.5 \mathrm{~g} / \mathrm{L}$ ) and were intended to be approximately equal to the observed amount of glucan solubilized in a previous $80 \mathrm{~g} / \mathrm{L}$ corn stover fermentation. The amount of cellobiose-grown cells added could theoretically represent an increase in cell concentration by $4 \mathrm{~g} / \mathrm{L}$, but the overall cell concentration or increase thereof was not measured.

As can be seen in Fig. 4, panel A, mid-fermentation addition of cellulose or cellobiose did not enhance solubilization relative to the water control. For the addition of cellulose, fractional carbohydrate solubilization was calculated based on the initial quantity of carbohydrate in the corn stover and the recovered carbohydrate after fermentation, with added cellulose not included in the initial amount of carbohydrate. An immediate increase in gas production accompanied both substrate additions (Fig. 4, panel B), from which we infer that the culture was active and substrate-limited in the absence of added substrate. This is mirrored by an increase in product formation in amounts expected if all added cellobiose and cellulose were utilized (see Additional file 1: Figure S6). Essentially complete fermentation of added substrate is also indicated by low amounts of residual sugars in cultures with and without added substrate (see Additional file 1: Supplemental S5). Extensive utilization of added substrates also suggests that limitation of media components and fermentation product inhibition are not in effect.

Although the highest FCS value was obtained with the mid-fermentation addition of $60 \mathrm{~mL}$ concentrated cell suspension, this was not determined to have a significant $(p>0.05)$ effect on carbohydrate solubilization compared to the water addition control (Fig. 4, panel A), and gas production was very similar to the water addition control (Fig. 4, panel B). The added cell culture proved to be viable as witnessed by normal growth on cellobiose or cellulose in serum bottle 


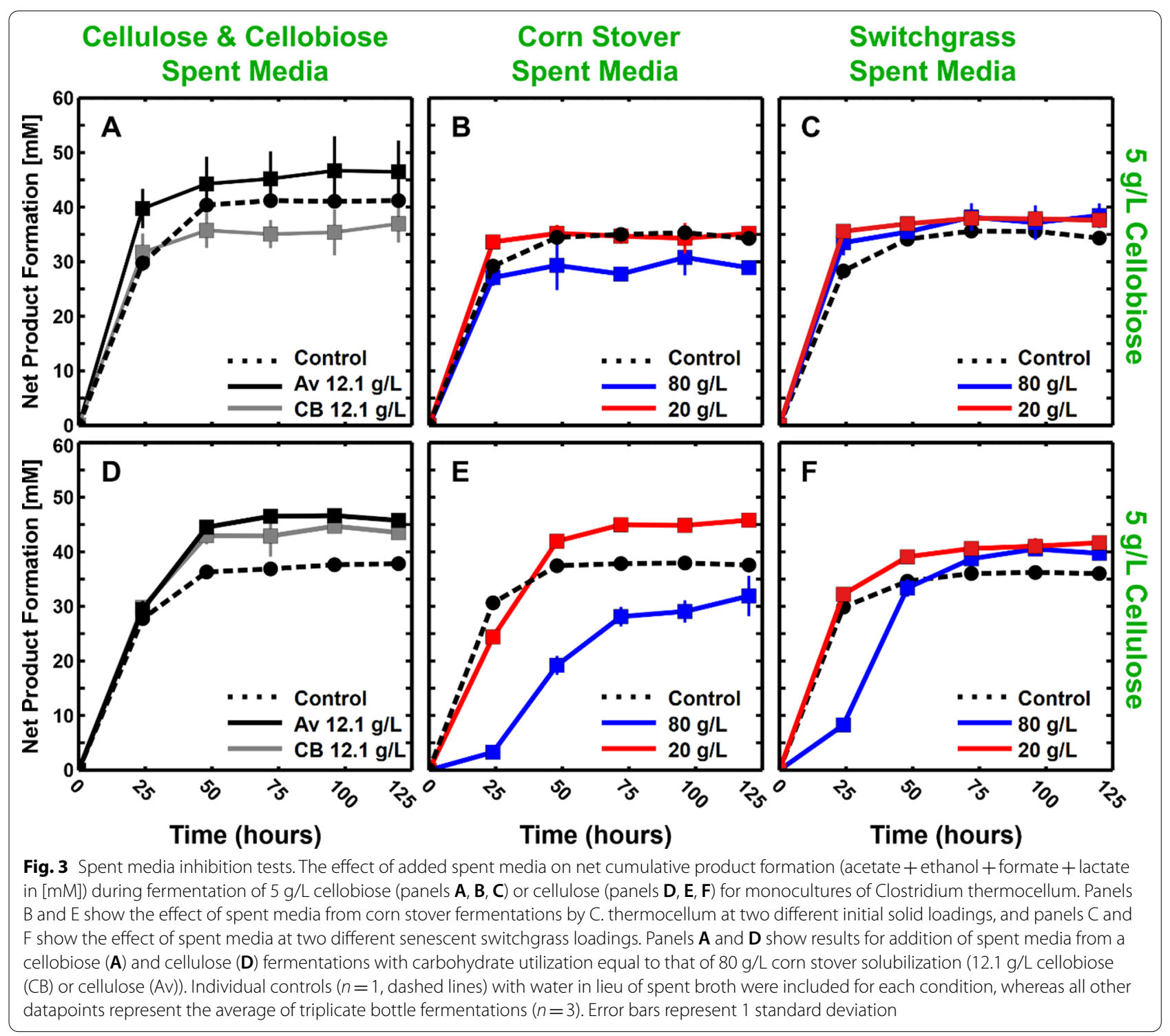

incubations inoculated at the same time with the same cell suspension as the addition experiment. We infer from these results that the amount of biocatalyst did not limit solubilization of the carbohydrate present in corn stover at a substrate loading of $80 \mathrm{~g} / \mathrm{L}$.

Whereas the fraction of corn stover carbohydrate solubilized was $0.556 \pm 0.011$ without added cells or substrate, this increased to $0.619 \pm 0.005$ for the water control. The difference between these values was statistically significant $(p=0.020)$. The addition of water brought the solids loading from $80 \mathrm{~g} / \mathrm{L}$ to $67 \mathrm{~g} / \mathrm{L}$ based on initial solids loaded, while the FCS value can be found between 60-80 $\mathrm{g} / \mathrm{L}$ initial solids loading as shown in Fig. 1.
Coculture experiments with low and high loadings of corn stover and switchgrass

We next examined the effect of culturing C. thermocellum with a hemicellulose-utilizing coculture partner, Thermoanaerobacterium saccharolyticum HG-8 ATCC 31960 for both high $(80 \mathrm{~g} / \mathrm{L})$ and low $(20 \mathrm{~g} / \mathrm{L})$ loadings of corn stover and switchgrass. For corn stover fermentations by monocultures and cocultures, FCS data are presented in Fig. 5 panel A and gas production data in panel B. Panels $C$ and D present the same data for switchgrass. The coculture demonstrated higher solubilization (5A and $5 \mathrm{C}$ ) and gas production (5B and 5D) for both feedstocks at low and high solid loadings. While the coculture showed higher solubilization than the monoculture, it 

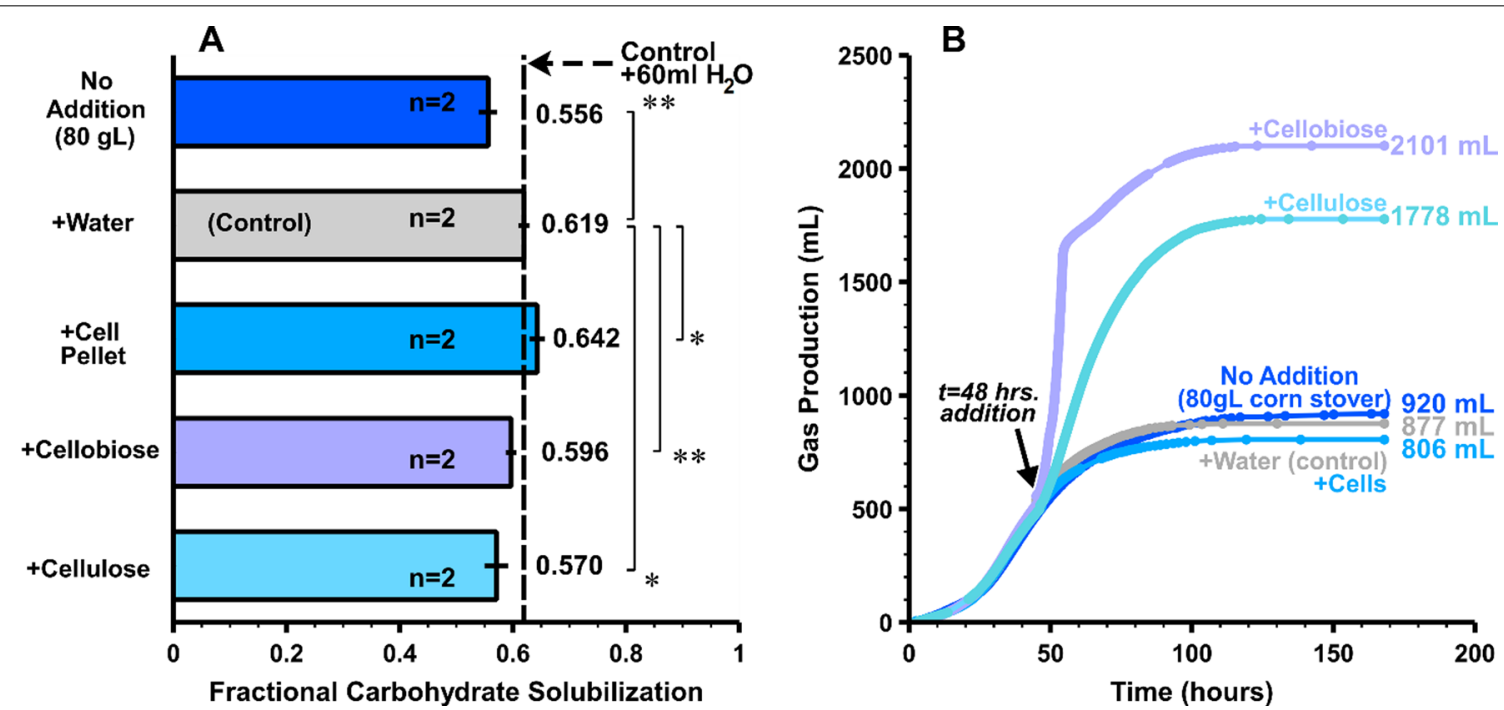

Fig. 4 Fermentation addition tests. Panel A Fractional carbohydrate solubilization for $80 \mathrm{~g} / \mathrm{L}$ corn stover with addition of cells (cellobiose-grown and centrifuged cell pellet), cellobiose solution, and suspended Avicel slurry at $48 \mathrm{~h}$ after inoculation versus a control (water only) or no addition $(n=2)$. Panel B Representative total gas production (cumulative $\mathrm{CO}_{2}$ and $\mathrm{H}_{2}$ ) for one of the duplicate reactors. Solubilization bars are averages of duplicate bioreactor runs, error bars represent 1 standard deviation. A single asterisk denotes a significance level of 0.1 , and double asterisks denote a significance level of 0.05 between different runs as indicated in the figure. The statistical analyses were performed using t-tests for two-samples assuming unequal variance, and the results are available as supplemental files

still exhibited diminishing solubilization as with increasing solid loadings.

Two-way ANOVA results indicate that the solids loading effect is significant at $\mathrm{p}<0.001$ for both substrates, while the coculture effect is significant at $p<0.001$ for corn stover and $p=0.063$ for switchgrass. The net increase in FCS due to the coculture was roughly twice as large for corn stover than for switchgrass, though the relative increases are consistent with the lower fractional solubilization observed for switchgrass monocultures throughout this study. Higher standard deviations were observed for switchgrass than for corn stover, consistent with the lower significance level per ANOVA testing.

The operating $\mathrm{pH}$ during cultivation for coculture experiments was lowered from 7.0 to 6.5 for this set of experiments to better accommodate growth of $T$. thermosaccharolyticum (Additional file 1: Figure S7). For $80 \mathrm{~g} / \mathrm{L}$ substrate loadings, this was determined to have a nonsignificant effect on the FCS by the monoculture (Fig. 6).

Figures 7 and 8 illustrate the effect of adding T. thermosaccharolyticum as a hemicellulose-utilizing coculture partner to cultures of $C$. thermocellum. Under the chosen conditions, the coculture partner fermented most but not all of the soluble pentose-rich oligosaccharides made available by $C$. thermocellum-mediated lignocellulose deconstruction. Based on carbohydrate solubilization and feedstock acetyl content $[55,56]$, the fraction of acetate that was fermentative product for monocultures and cocultures on corn stover ranged between $77.4-77.7 \%$ and $82.0-83.9 \%$, respectively. Similarly, for switchgrass, values ranged between $56.4-77.0 \%$ and $79.5-90.6 \%$, respectively (Additional file 1: Table S10). Fractional carbohydrate solubilization and utilization data are presented in Table 1 for the experiments depicted in Figs. 5, $6,7,8$.

It may be observed that fractional carbohydrate solubilization is sensitive to solid loading, whereas the fractional utilization of solubilized carbohydrates is not. For cocultures on either feedstock, roughly $5 \%$ and $20 \%$ of the solubilized glucose- and xylose-oligomers, respectively, are not utilized.

A linear relationship was observed for fractional solubilization of xylan and glucan for monocultures and cocultures fermenting both corn stover and switchgrass at various substrate loadings (Fig. 9). This relationship is largely maintained across solid loadings and culture type. This would suggest that solid loading and culture type does not bias the solubilization activity either towards or away from glucose (or xylose).

\section{Discussion}

Here, we document declining solubilization with increasing solids loading over a range of 20 to $80 \mathrm{~g} / \mathrm{L}$ for batch monocultures of $C$. thermocellum fermenting either corn stover or senescent switchgrass. Our observation of this trend is consistent with results of both Verbeke et al. and 

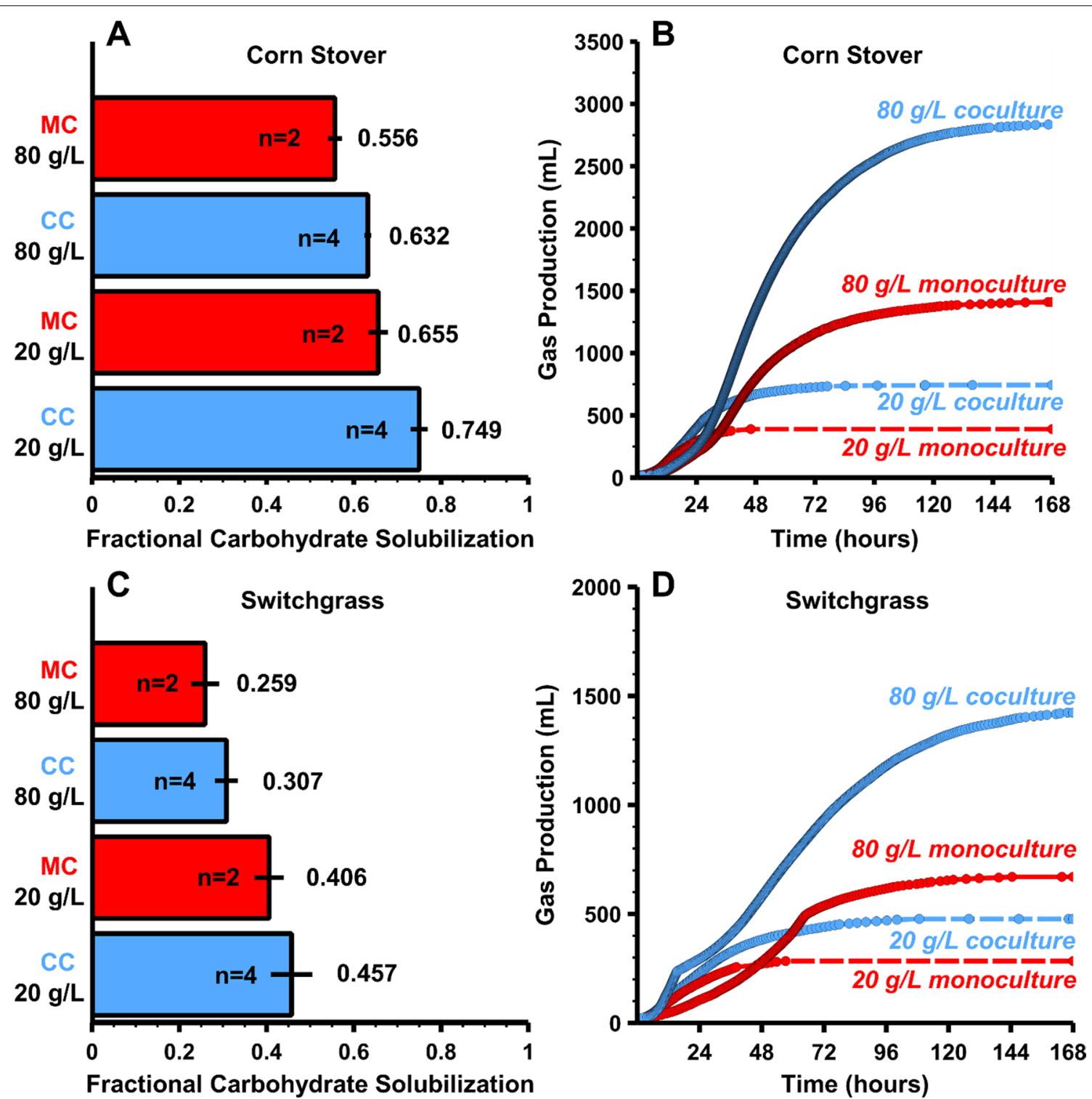

Fig. 5 Monocultures and cocultures solubilization and gas production. Panels $\mathbf{A}$ and $\mathbf{C}$ Fractional carbohydrate solubilization of $20 \mathrm{~g} / \mathrm{L}$ and $80 \mathrm{~g} / \mathrm{L}$ corn stover $(\mathbf{A})$ and senescent switchgrass $(\mathbf{C})$ by monocultures of Clostridium thermocellum and cocultures of Thermoanaerobacterium saccharolyticum at $\mathrm{pH}$ 6.5. Panels $\mathbf{B}$ and $\mathbf{D}$ Representative total gas (cumulative $\mathrm{CO}_{2}$ and $\mathrm{H}_{2}$ ) production for one of the duplicate reactors of 20 and $80 \mathrm{~g} / \mathrm{L}$ corn stover (B) and senescent switchgrass (D) fermentations at pH 6.5. Solubilization bars are averages of duplicate bioreactors runs, and error bars represent 1 standard deviation

Shao et al. on mid-season switchgrass at various solids loadings $[19,52]$. Comparing monocultures with $80 \mathrm{~g} / \mathrm{L}$ and $20 \mathrm{~g} / \mathrm{L}$ substrate loadings with no pretreatment other than autoclaving, final total carbohydrate solubilization declined from 0.695 to 0.565 for corn stover and from 0.399 to 0.243 for switchgrass. Data at intermediate solids loading indicate a roughly linear declining solubilization trend for both substrates. Remediation of this effect is likely necessary for commercial application acknowledging that substrate loadings about twofold higher than the maximum studied herein are generally envisioned for economically viable production of ethanol from lignocellulose [2,3]. Such remediation would be greatly informed, and likely require, understanding the factor(s) responsible for the declining fractional solubilization trend observed here.

As reported previously, we routinely observe nearcomplete utilization of Avicel-cellulose up to $120 \mathrm{~g} / \mathrm{L}$ by C. thermocellum cultures [49-51], which is accompanied by concentrations of fermentation products over twice those observed herein with corn stover or switchgrass at $80 \mathrm{~g} / \mathrm{L}$. In light of these results, both inhibition 


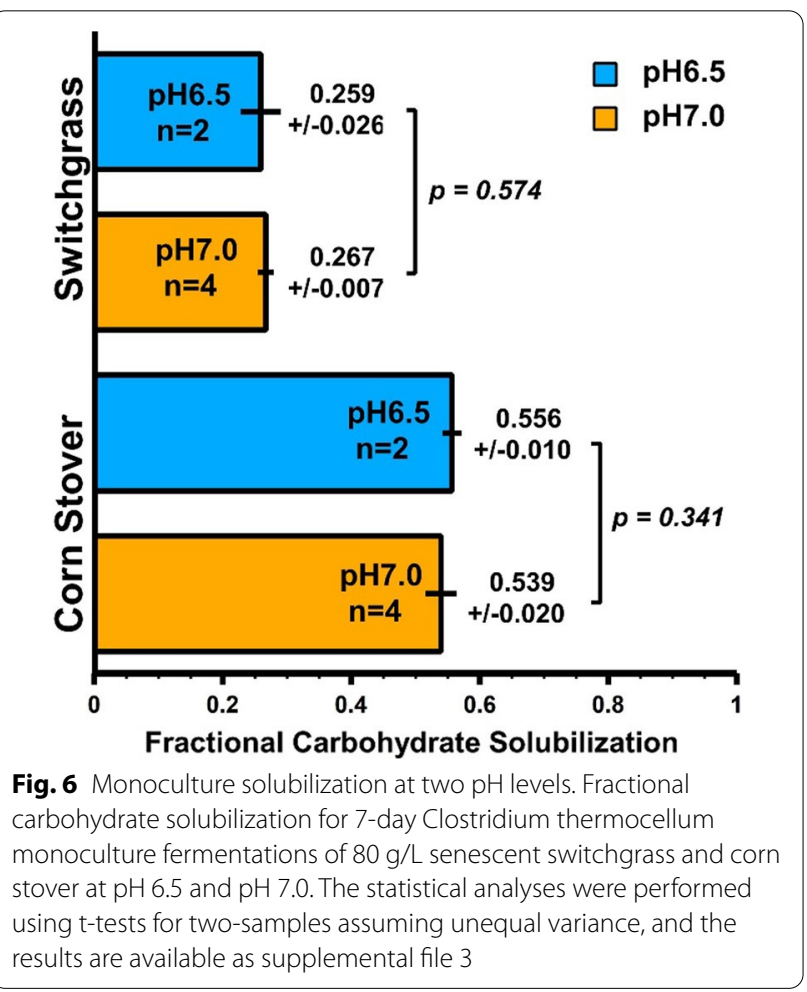

by fermentation products and limitation by inadequate amounts of growth medium components seem unlikely to explain the declining fractional solubilization trend. Several alternative hypotheses for the basis of this phenomenon were tested but did not confirm specific factors. Accumulation of liquid-phase inhibitors is a common explanation for cellulase inhibition, yet in this study, C. thermocellum was able to overcome a transient delay in cellulose utilization in the presence of spent broth from high lignocellulose loadings. Addition of spent broth from fermentation of 20 and $80 \mathrm{~g} / \mathrm{L}$ corn stover and switchgrass (Fig. 3) resulted in little to no impact on cellobiose fermentation, indicating that fermentation of glucan solubilization products was not inhibited, and little if any long-term impact on the generation of fermentation products from cellulose, suggesting that cellulase activity is not irreversibly inhibited. In this respect, our results differ from those of Beri et al. who observed inhibition from corn fiber spent broth on cellobiose incubations by C. thermocellum monocultures [20]. It should be noted that there are several compounding factors that obscure comparisons between spent broth experiments, including cultivation conditions and spent broth preparation, and similar results for corn stover and corn fiber would not necessarily be expected considering the markedly different feedstock composition and experimental design $[20,28]$. For cellulose incubations in the presence of switchgrass spent broth, Verbeke et al. observed reductions in solubilization for $17.5 \mathrm{~g} / \mathrm{L}$ cellulose, but showed little difference in net-end product concentrations, as we also observed [52]. Shao et al. (2020) observed decreased cellulose conversion due to added spent broth measured at $24 \mathrm{~h}$, however measurements were not taken at longer times to determine if conversion with added broth
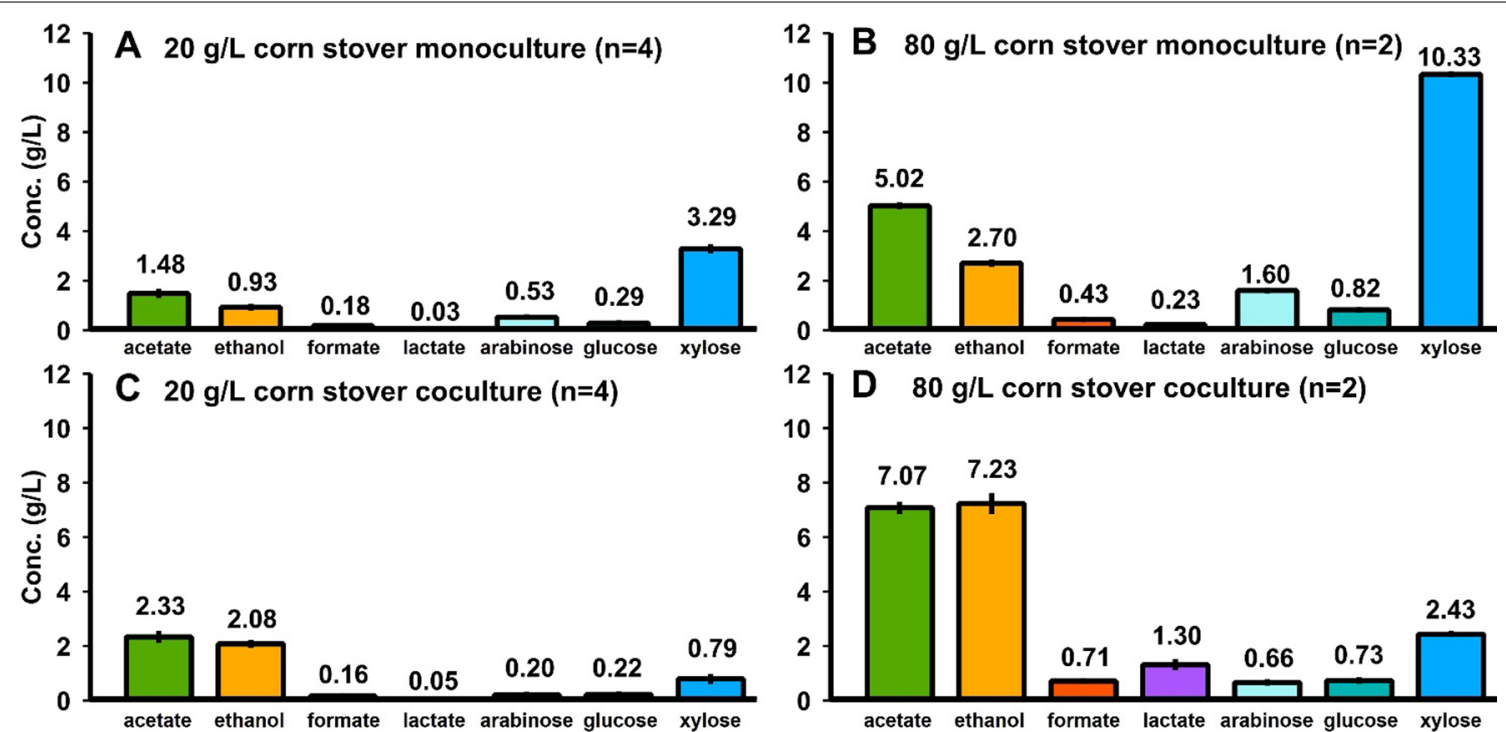

Fig. 7 Monocultures and cocultures fermentation products and residual soluble carbohydrate for corn stover. 7-day fermentations of corn stover by monocultures at loadings of $20 \mathrm{~g} / \mathrm{L}$ (A) and $80 \mathrm{~g} / \mathrm{L}$ (B) and cocultures at loadings of $20 \mathrm{~g} / \mathrm{L}$ (C) and $80 \mathrm{~g} / \mathrm{L}$ (D). Residual soluble carbohydrate was quantified in monomeric form after mild acid hydrolysis of the supernatant 

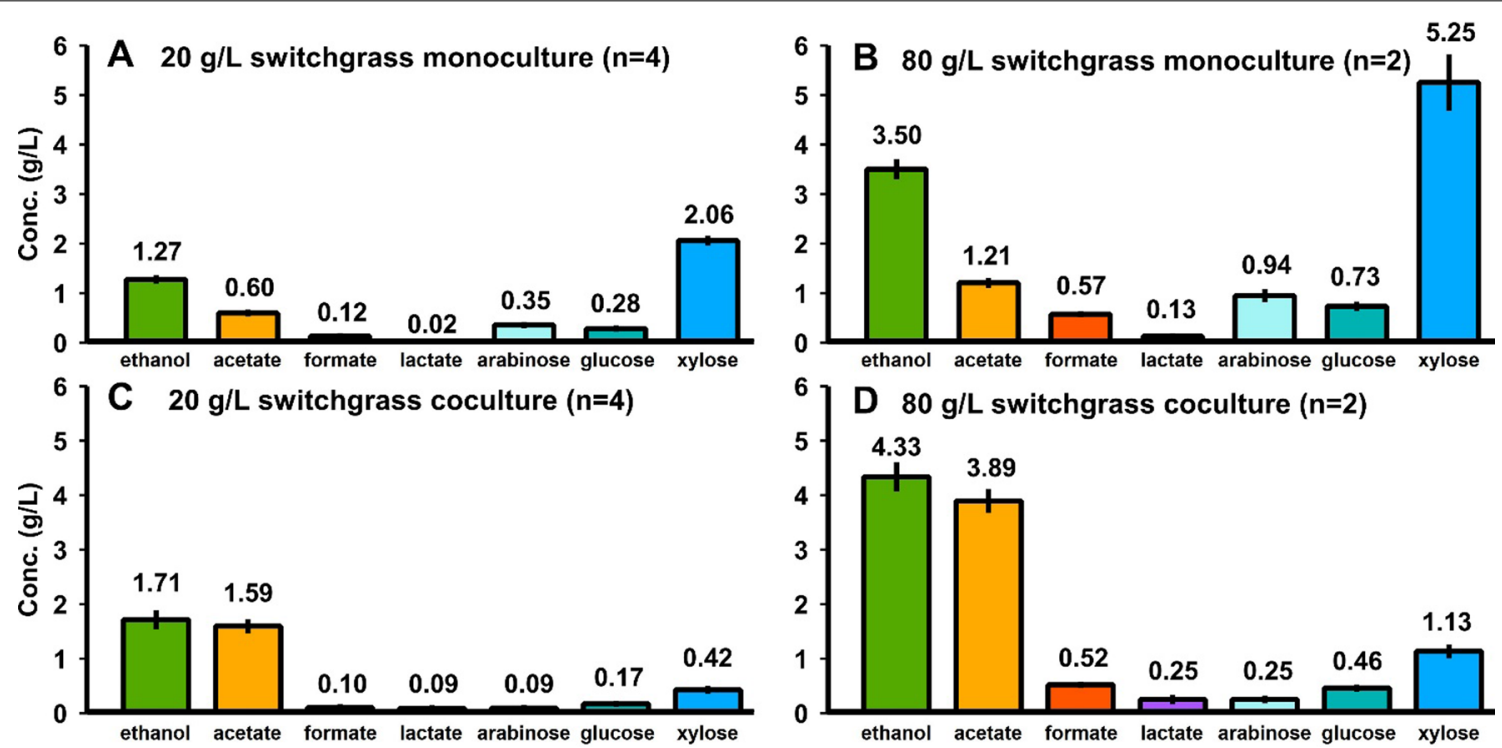

Fig. 8 Monocultures and cocultures fermentation products and residual soluble carbohydrate for switchgrass. 7-day fermentations of senescent switchgrass by monocultures at loadings of $20 \mathrm{~g} / \mathrm{L}(\mathbf{A})$ and $80 \mathrm{~g} / \mathrm{L}(\mathbf{B})$ and cocultures at loadings of $20 \mathrm{~g} / \mathrm{L}(\mathbf{C})$ and $80 \mathrm{~g} / \mathrm{L}$ (D). Residual soluble carbohydrate was quantified in monomeric form after mild acid hydrolysis of the supernatant

Table 1 Comparison of carbohydrate solubilization and utilization for mono- and cocultures

\begin{tabular}{|c|c|c|c|c|}
\hline & Solid loading & $\begin{array}{l}\text { Fractional carbohydrate } \\
\text { solubilization }\end{array}$ & $\begin{array}{l}\text { Fractional utilization of } \\
\text { solubilized glucose }\end{array}$ & $\begin{array}{l}\text { Fractional utilization } \\
\text { of solubilized xylose }\end{array}$ \\
\hline \multicolumn{5}{|l|}{ Corn stover } \\
\hline \multirow[t]{2}{*}{ Monoculture } & $20 \mathrm{~g} / \mathrm{L}$ & $0.656 \pm 0.017$ & $0.938 \pm 0.002$ & - \\
\hline & $80 \mathrm{~g} / \mathrm{L}$ & $0.557 \pm 0.010$ & $0.946 \pm 0.001$ & - \\
\hline \multirow[t]{2}{*}{ Coculture } & $20 \mathrm{~g} / \mathrm{L}$ & $0.749 \pm 0.014$ & $0.957 \pm 0.001$ & $0.779 \pm 0.027$ \\
\hline & $80 \mathrm{~g} / \mathrm{L}$ & $0.632 \pm 0.002$ & $0.958 \pm 0.001$ & $0.798 \pm 0.002$ \\
\hline \multicolumn{5}{|l|}{ Switchgrass } \\
\hline \multirow[t]{2}{*}{ Monoculture } & $20 \mathrm{~g} / \mathrm{L}$ & $0.406 \pm 0.028$ & $0.904 \pm 0.015$ & - \\
\hline & $80 \mathrm{~g} / \mathrm{L}$ & $0.259 \pm 0.026$ & $0.910 \pm 0.003$ & - \\
\hline \multirow[t]{2}{*}{ Coculture } & $20 \mathrm{~g} / \mathrm{L}$ & $0.457 \pm 0.042$ & $0.952 \pm 0.002$ & $0.817 \pm 0.002$ \\
\hline & $80 \mathrm{~g} / \mathrm{L}$ & $0.308 \pm 0.021$ & $0.954 \pm 0.000$ & $0.821 \pm 0.002$ \\
\hline
\end{tabular}

Fractional sugar utilization calculated as one minus the mass of sugars found in the fermentation broth over the theoretical mass of sugars that have been solubilized based on fermented and unfermented solids. Sugar concentrations in the fermentation broth quantified in monomeric form via mild acid hydrolysis of the supernatant. No fractional utilization of xylose was detected in the monocultures

eventually equaled the controls as was observed in Fig. 3 [19].

Mid-fermentation addition of cellobiose or cellulose to $80 \mathrm{~g} / \mathrm{L}$ corn stover $C$. thermocellum monocultures resulted in a dramatic increase in gas formation compared to controls without substrate added, but no significant increase in FCS. This suggests that the culture and its cellulases were active and not limited in utilizing additional (model) substrate, but rather had stopped solubilizing additional substrate from lignocellulose. Note that the additional utilization of cellobiose and cellulose could have resulted in an increase in cellular biomass or posed an opportunity for new cellular biomass to be generated. Furthermore, no significant increase in solubilization was observed for additions of biocatalyst (concentrated cells) suggesting limitations in solubilization could be more closely related to the lignocellulosic substrate rather than C. thermocellum's enzymatic machinery. An increase in FCS was observed for an addition of $60 \mathrm{ml}$ water to a 300$\mathrm{ml}$ culture which effectively diluted the initial substrate loading at 80 to $66.7 \mathrm{~g} / \mathrm{L}$. Linear interpolation of carbohydrate solubilization at 60 and $80 \mathrm{~g} / \mathrm{L}$ from Fig. 1 gives an expected solubilization of 0.606 at a substrate loading of $66.7 \mathrm{~g} / \mathrm{L}$, which is very close to the observed value of 


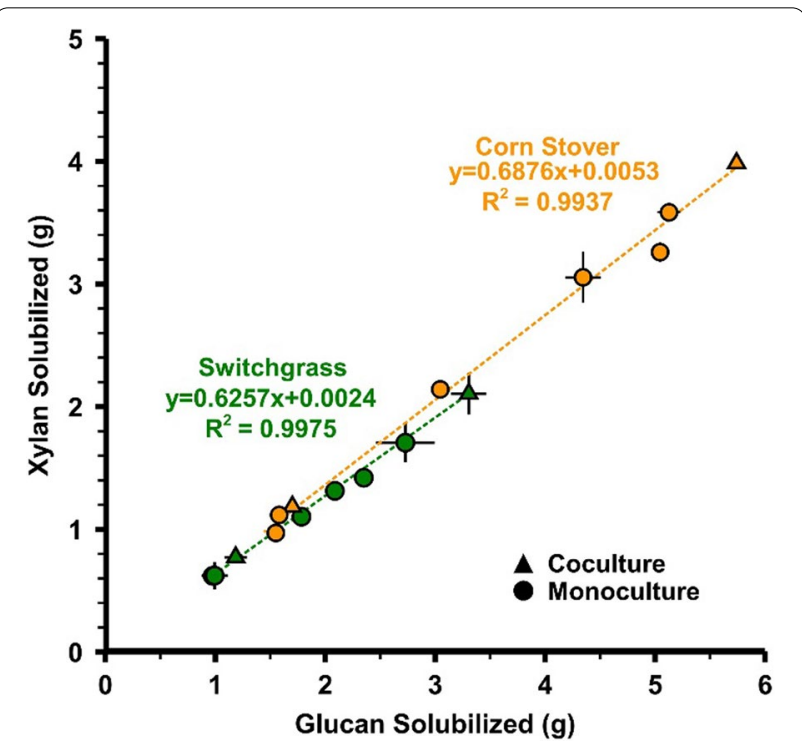

Fig. 9 Linear solubilization ratio between xylan and glucan for different cultivation conditions. Datapoints are averages of the duplicate fermentations depicted in Fig. 1 and Fig. 5 and error bars represent 1 standard deviation. Trendlines are calculated using combined datasets for each feedstock which represent two culture types (mono- and cocultures) and multiple solid loadings (20, 40, 60, $80 \mathrm{~g} / \mathrm{L})$

0.619. Thus, results with different initial substrate loadings are very nearly recapitulated by a water dilution during active fermentation.

Coculturing $C$. thermocellum with the hemicellulosefermenting Thermoanaerobacterium thermosaccharolyticum increased solubilization compared to monocultures at both $20 \mathrm{~g} / \mathrm{L}$ and $80 \mathrm{~g} / \mathrm{L}$ substrate loadings for corn stover $(p<0.001)$ and switchgrass $(p=0.063)$. Inclusion of $T$. thermosaccharolyticum as a coculture partner did not, however, ameliorate declining solubilization as was observed at $40 \mathrm{~g} / \mathrm{L}$ corn fiber by Beri et al. (from 67 to 93\%) although the absolute amount of carbohydrates solubilized and utilized is much higher for corn stover [20]. For each feedstock, we observed a consistent fraction of hemicellulose sugars are being solubilized but not utilized regardless of solid loadings (Table 2). Our results are consistent with certain linkages present in soluble products of Clostridium thermocellum-mediated hemicellulose deconstruction being inaccessible to the array of carbohydrate active enzymes of $T$. thermosaccharolyticum, as had been previously observed by Beri et al. for corn fiber [28].

To be consistent with the observations reported herein, a proposed mechanism for declining fractional carbohydrate solubilization with increasing solids would need to be lignocellulose-specific, involve factors other than nutrient limitation and inhibition by liquid-phase products of fermentation or deconstruction, not be due to inactive microbial cells or CAZymes, be reversed by liquid-phase dilution, and partially reversed by addition of a hemicellulose-fermenting coculture partner. In general, a mechanism involving decreasing lignocellulose accessibility with increasing substrate loading seems mostly likely to us. It has been previously reported that xylan and pentose-rich oligosaccharides adsorb onto cellulose surfaces [37, 58-61], and cellulase performance is generally enhanced in the presence of hemicellulolytic enzymes [37-40]. Noting that dilution of the liquid phase would be expected to cause adsorbed oligosaccharides to enter solution by Le Chatelier's principle, impediment of deconstruction by adsorbed oligosaccharides would appear to be a plausible mechanism for C. thermocellum which remains to be definitively proven.

\section{Conclusions}

Decreasing fractional carbohydrate solubilization with increasing substrate loading was observed for monocultures of $C$. thermocellum and coculture fermentations of C. thermocellum and T. thermosaccharolyticum fermenting corn stover and senescent switchgrass with no pretreatment other than autoclaving. Results of experiments involving spent media addition do not support a major role for inhibitors present in the liquid phase. Substrate addition experiments confirm that $C$. thermocellum and its CAZymes remain capable of converting model substrates during the middle of lignocellulose fermentation at the maximum substrate loading tested $(80 \mathrm{~g} / \mathrm{L})$. Substrate dilution reverses the observed decrease in fractional carbohydrate solubilization at increasing substrate loading, and coculture of $C$. thermocellum with T. thermosaccharolyticum, which ferments hemicellulose, increases fractional carbohydrate solubilization

Table 2 Lignocellulose feedstock characteristics of $60^{\circ} \mathrm{C}$ oven-dried unfermented feedstock

\begin{tabular}{|c|c|c|c|c|c|c|}
\hline \multirow[t]{2}{*}{ Feedstock } & \multicolumn{3}{|c|}{ Carbohydrates (g/g) } & \multirow{2}{*}{$\begin{array}{l}\text { Moisture } \\
\text { (wt.\%) }\end{array}$} & \multirow{2}{*}{$\begin{array}{l}\text { Ash } \\
\text { (wt.\%) }\end{array}$} & \multirow{2}{*}{$\begin{array}{l}\text { Lignin } \\
\text { (wt.\%) }\end{array}$} \\
\hline & Glucose & Xylose & Arabinose & & & \\
\hline POET corn stover A & $0.366 \pm 0.005$ & $0.274 \pm 0.005$ & $0.032 \pm 0.000$ & $1.310 \pm 0.509$ & $13.010 \pm 0.000$ & $18.333 \pm 0.005$ \\
\hline POET corn stover B & $0.417 \pm 0.002$ & $0.301 \pm 0.000$ & $0.0405 \pm 0.000$ & $1.165 \pm 0.176$ & $6.769 \pm 0.000$ & $16.191 \pm 0.001$ \\
\hline ERNST senescent switchgrass & $0.435 \pm 0.000$ & $0.298 \pm 0.000$ & $0.029 \pm 0.000$ & $1.170 \pm 0.339$ & $2.961 \pm 0.000$ & $19.483 \pm 0.002$ \\
\hline
\end{tabular}


compared to $C$. thermocellum monocultures at both lower $(20 \mathrm{~g} / \mathrm{L})$ and higher $(80 \mathrm{~g} / \mathrm{L})$ loadings of both corn stover and switchgrass. For both monocultures and cocultures, regardless of solid loading, there remains a consistent fraction of carbohydrates that undergo solubilization, but not utilization. This suggests that some carbohydrates are unaffected by the existing suite of CAZymes present in the culture. Impediment of deconstruction by adsorbed oligosaccharides would appear to be a plausible mechanism for the observed trend of declining solubilization with increasing substrate loading, although this remains to be conclusively shown.

\section{Methods}

\section{Substrates}

Carbohydrate solubilization of two lignocellulosic feedstocks were characterized across various solid loadings. Corn stover was a gift from POET Research Inc (Sioux Falls, SD) pre-milled at $1 / 8^{\prime \prime}$ size material. Due to material limitations, a separate batch of corn stover (also from POET Research Inc) was used for experiments comparing monocultures and cocultures. Senescent lowland 'Timber' switchgrass was a gift from Ernst Seeds (Meadville PA, USA), planted in May 2016, harvested December 2018 and dried at $300-400^{\circ} \mathrm{F}$ upon harvesting and milled at $1 / 4$ " size for storage. Prior to characterization and use in experiments, both feedstocks were milled to pass through a $0.5-\mathrm{mm}$ sieve on a Retsch ZM 200 centrifugal mill (Verder Scientific, Newton PA) [7]. Carbohydrate content was determined by quantitative saccharification (QS) with $72 \%(\mathrm{w} / \mathrm{w}) \mathrm{H}_{2} \mathrm{SO}_{4}$ (Fisher, Waltham MA), as described in Sluiter et al. [62]. Post-QS-sample supernatant was filtered via Spin-X centrifuge tubes $(0.22 \mu \mathrm{m}$ nylon) (Corning, Corning NY) before HPLC analysis. The acid-hydrolyzed monomeric sugars arabinose, glucose, and xylose were quantified by refractive index detection and separated via HPLC (Waters, Milford MA) with an Aminex ${ }^{\circledR}$ HPX-87H column (Bio-Rad, Hercules CA) operating at $60{ }^{\circ} \mathrm{C}, 2.5 \mathrm{mM} \mathrm{H}_{2} \mathrm{SO}_{4}$ eluent, at a flowrate of $0.6 \mathrm{~mL} / \mathrm{min}$ [7]. Moisture content was determined using an A\&D MX-50 Moisture Analyzer (San Jose, CA). Ash content was determined according to the method described in Sluiter et al. [63] using a Dentsply-Ceramco Vulcan 3-550 muffle furnace (Dentsply-Sirona, York, PA) (Ceramco, Conway, NH). Lignin content was approximated as $100 \%$ minus the sum of carbohydrates, moisture, and ash content [63]. Each value recorded in Table 2 was determined using feedstocks dried at $60{ }^{\circ} \mathrm{C}$, whereas fractional carbohydrate solubilization was calculated using air-dried, room temperature unfermented feedstock. Average carbohydrate content was determined in triplicate and moisture, ash, and lignin in duplicate.

\section{Microbial strains and growth media}

Clostridium thermocellum DSM1313 (LL1004) was obtained from the Deutsche Sammlung von Mikroorganismen und Zellkulturen GmbH (DSMZ, Liebniz, Ger.). Thermoanaerobacterium thermosaccharolyticum HG-8 ATCC 31960 (LL1244) was obtained from the American Type Culture Collection (ATCC, Manassas, VA). Inocula were prepared by culturing $C$. thermocellum on MTC [64] and $50 \mathrm{~g} / \mathrm{L}$ microcrystalline cellulose (Avicel $^{\circledR}$ PH105, FMC biopolymers, Philadelphia PA) in a pH-controlled 1.2-L Sartorius bioreactor. During midgrowth phase, $30-\mathrm{mL}$ cell culture aliquots were transferred to $50-\mathrm{mL}$ serum bottles. Cell culture aliquots were stored at $-80^{\circ} \mathrm{C}$ and were slowly thawed several hours before bioreactor inoculation. T. thermosaccharolyticum inoculum was cultured on modified CTFüD medium substituted with D-xylose for cellobiose [65]. Inoculum was re-seeded several hours prior to bioreactor inoculation in order to ensure culture viability, which was added to bioreactors at $4 \%(\mathrm{v} / \mathrm{v})$. Defined Medium for Thermophilic Clostridia (MTC) was prepared as described prior [64]; solution $\mathrm{B}$ had bioreactor concentrations of $2.12 \mathrm{~g} / \mathrm{L}$ potassium citrate monohydrate $\left(\mathrm{C}_{6} \mathrm{H}_{7} \mathrm{O}_{8} \mathrm{~K}_{3}\right)$, $1.25 \mathrm{~g} / \mathrm{L}$ citric acid monohydrate $\left(\mathrm{C}_{6} \mathrm{H}_{8} \mathrm{O}_{7} \cdot \mathrm{H}_{2} \mathrm{O}\right), 1.0 \mathrm{~g} / \mathrm{L}$ $\mathrm{Na}_{2} \mathrm{SO}_{4}, 1 \mathrm{~g} / \mathrm{L} \mathrm{KH}_{2} \mathrm{PO}_{4}, 2.5 \mathrm{~g} / \mathrm{L} \mathrm{NaHCO}$, and was added at $4 \%(\mathrm{v} / \mathrm{v})$. Solution $\mathrm{C}$ had a bioreactor concentration of $2.0 \mathrm{~g} / \mathrm{L}$ urea $\left(\mathrm{CH}_{4} \mathrm{~N}_{2} \mathrm{O}\right)$ and was added at $2 \%(\mathrm{v} / \mathrm{v})$. Solution $\mathrm{D}$ had bioreactor concentrations of $1.0 \mathrm{~g} / \mathrm{L} \mathrm{MgCl}_{2}$ - $6 \mathrm{H}_{2} \mathrm{O}, 0.2 \mathrm{~g} / \mathrm{L} \mathrm{CaCl}, 0.1 \mathrm{~g} / \mathrm{L} \mathrm{FeCl}_{2} \cdot 4 \mathrm{H}_{2} \mathrm{O}, 1.0 \mathrm{~g} / \mathrm{L}$ L-cysteine $\mathrm{HCL}$ monohydrate $\left(\mathrm{C}_{3} \mathrm{H}_{7} \mathrm{NO}_{2} \mathrm{~S} \cdot \mathrm{HCl} \cdot \mathrm{H}_{2} \mathrm{O}\right)$, and was added at $2 \%(\mathrm{v} / \mathrm{v})$. Solution $\mathrm{E}$ had bioreactor concentrations of $0.02 \mathrm{~g} / \mathrm{L}$ pyridoxamine dihydrochloride, $0.004 \mathrm{~g} / \mathrm{L}$ 4-aminobenzoic acid, $0.002 \mathrm{~g} / \mathrm{L}$ D-biotin, $0.002 \mathrm{~g} / \mathrm{L}$ vitamin $B_{12}$, and was added at $2 \%(\mathrm{v} / \mathrm{v})$. Solution TE had bioreactor concentrations of $0.00625 \mathrm{~g} / \mathrm{L} \mathrm{MnCl}_{2}$ . $4 \mathrm{H}_{2} \mathrm{O}, 0.0025 \mathrm{~g} / \mathrm{L} \mathrm{ZnCl}, 0.000625 \mathrm{~g} / \mathrm{L} \mathrm{CoCl}_{2} \cdot 6 \mathrm{H}_{2} \mathrm{O}$, $0.000625 \mathrm{~g} / \mathrm{L} \mathrm{NiCl}_{2} \cdot 6 \mathrm{H}_{2} \mathrm{O}, 0.000625 \mathrm{~g} / \mathrm{L} \mathrm{CuSO}_{4} \cdot 5 \mathrm{H}_{2} \mathrm{O}$, $0.000625 \mathrm{~g} / \mathrm{L} \mathrm{H}_{3} \mathrm{BO}_{3}, 0.000625 \mathrm{~g} / \mathrm{L} \mathrm{Na}_{2} \mathrm{MoO}_{4} \cdot 2 \mathrm{H}_{2} \mathrm{O}$, and was added at $0.5 \%(\mathrm{v} / \mathrm{v})$. Each MTC solution was purged by 20 cycles of alternating $\mathrm{N}_{2}$ gas and Vacuum for $45 \mathrm{~s}$ each. After purging, solution D was autoclaved for 30 min on liquid cycle.

\section{Monoculture fermentations at various solid loadings}

All lignocellulose fermentations were performed at $300 \mathrm{~mL}$ working volume in 0.5-L Sartorius Qplus bioreactors (Sartorius, Bohemia NY). Each solids loading was run at least in duplicate $(n=2)$. Lignocellulosic feedstocks were suspended in Milli-Q water (MilliporeSigma, Burlington MA) and autoclaved for $90 \mathrm{~min}$ on a liquid/slow exhaust cycle. Overnight, the bioreactor's headspace was sparged with 'ultra pure' $\mathrm{N}_{2}$ gas (Airgas, White River Junction VT) while being stirred at 300 RPM 
at $55^{\circ} \mathrm{C}$. After sparging the bioreactors, media solutions were added to the lignocellulose slurry via a $0.2 \mu \mathrm{m}$ polyethersulfone (PES) sterile syringe filter (Corning, Corning NY).

Prior to inoculation, the $\mathrm{pH}$ was controlled at 7.0 or 6.5 using a gel-filled $\mathrm{pH}$ probe (Mettler-Toledo, Billerica MA) and automatic addition of $4 \mathrm{~N} \mathrm{KOH}$ (Fisher, Waltham MA) via a peristaltic pump in the Sartorius control tower. Online gas production was monitored with a milligas flow meter (Ritter, Hawthorne NY) filled with $0.5 \mathrm{~N} \mathrm{HCl}$. Total volumetric gas production data were recorded by the accompanying Rigamo software. $C$. thermocellum inoculum was added at $2 \%(\mathrm{v} / \mathrm{v})$, and the fermentations proceeded for $168 \mathrm{~h}$.

\section{Harvesting residual solids and determination of carbohydrate solubilization and fermentation products} After fermentation, the bioreactor contents were harvested as a whole and centrifuged for $15 \mathrm{~min}$ at $16,000 \times g$ at $4{ }^{\circ} \mathrm{C}$ on an Avanti J-26S XP centrifuge using rotor JA-10. Both the residual solids and supernatant were collected to determine their respective carbohydrate concentrations. Fractional carbohydrate solubilization is calculated as the difference between carbohydrate mass in the unfermented feedstock versus the residual solids. Carbohydrate content in the residual solids was determined via QS as described in the feedstock material section. Similarly, the carbohydrate content of the supernatant was determined using a mild-acid hydrolysis step named liquid quantitative saccharification (LQS) adjusted from Sluiter et al. [62]. Analysis of fermentation products (acetate, ethanol, formate, lactate) was performed by mixing $35 \mu \mathrm{L} 10 \%(\mathrm{v} / \mathrm{v}) \mathrm{H}_{2} \mathrm{SO}_{4}$ and $700 \mu \mathrm{L}$ fermentation supernatant and allowing the solution to sit for $>5 \mathrm{~min}$ to denature proteins. The acidified solution was spun down in the microcentrifuge at $21,130 \times \mathrm{g}$ and the supernatant was filtered via Spin-X centrifuge tubes $(0.22 \mu \mathrm{m}$ nylon $)$ (Corning, Corning NY). The filtrate was quantified for products via HPLC and quantified by comparison to standard solutions. Relative acetate contributions from non-fermentative lignocellulose deconstruction were estimated using carbohydrate solubilization values and feedstock acetyl content as determined by Kumar et al. [56] and Wyman et al. (55) (Additional file 1: Table S10).

\section{Bottle fermentations with lignocellulose fermentation spent media}

Serum bottles $(30 \mathrm{~mL})$ were prepared by adding either $\mathrm{D}(+)$ cellobiose (MilliporeSigma, Burlington MA), or microcrystalline cellulose (Avicel ${ }^{\circledR}$ PH105, FMC biopolymers, Philadelphia PA) to MilliQ water, purged with nitrogen gas, and autoclaved for $30 \mathrm{~min}$ on a liquid cycle. Carbon substrates were concentrated such that the concentration prior to inoculation was either $5.0 \mathrm{~g} / \mathrm{L}$ cellulose or cellobiose. The final volume $(20 \mathrm{~mL})$ consisted of $75 \%$ spent media (or sterile and anaerobic water for controls) and $25 \%$ fresh substrate and MTC media. To buffer $\mathrm{pH}$, solution A was also included at a concentration, prior to inoculation, of $5.0 \mathrm{~g} / \mathrm{L}$ morpholinopropane sulfonic acid (MOPS) sodium salt and was added at $2 \%(\mathrm{v} / \mathrm{v})$. MTC was added to each bottle as described above. However, for bottle fermentations solutions A, B, and $C$ were autoclaved for $30 \mathrm{~min}$ on liquid cycle, and not filter-sterilized.

Supernatant was collected from the high solids monoculture batch fermentations described above. Harvesting the residual solids, collecting and preparing the supernatant, and inoculating bottle fermentations were all performed on the same day. The liquid phase from $80 \mathrm{~g} / \mathrm{L}$ corn stover, $20 \mathrm{~g} / \mathrm{L}$ corn stover, $80 \mathrm{~g} / \mathrm{L}$ switchgrass and $20 \mathrm{~g} / \mathrm{L}$ switchgrass fermentations were used for bottle experiments. The supernatant was subject to a second centrifugation for $10 \mathrm{~min}$ at 50,000 $\times g$ on an Avanti J-26S $\mathrm{XP}$ centrifuge using a JA-25.50 rotor. The supernatant was then vacuum filtered with a glass fiber membrane prefilter (MilliporeSigma, Burlington MA) and then vacuum filtered with a 0.45-um nylon membrane filter (MilliporeSigma, Burlington MA). Lastly, the supernatant was added through a 0.2-um PES syringe sterile filter into an empty and autoclaved serum bottle and was aseptically purged for 20 cycles as previously described.

In addition to collecting lignocellulosic supernatant, supernatant from batch fermentations on model substrates, cellobiose and cellulose, were collected for bottle experiments. Monoculture batch fermentations of cellobiose and cellulose were performed as described above for $0.5 \mathrm{~L}$ final volume in 1.2-L Sartorius bioreactors. Both substrates were loaded at a bioreactor concentration of $12.1 \mathrm{~g} / \mathrm{L}$, which is approximately equal to the amount of glucan solubilized in an $80 \mathrm{~g} / \mathrm{L}$ corn stover fermentation as determined in prior experiments. The model substrate cultures were harvested at $48 \mathrm{~h}$ which corresponded to approximately $24 \mathrm{~h}$ after base addition had stopped. Supernatant was collected and filtered in the same procedure described above for lignocellulosic supernatant.

A one-way release valve was used aseptically to equilibrate pressure before inoculation. Bottles, run in triplicate $(n=3)$, were inoculated $2 \%(\mathrm{v} / \mathrm{v})$ with a $-80{ }^{\circ} \mathrm{C}$ bottle of $C$. thermocellum as described above. Bottles were cultivated at $55{ }^{\circ} \mathrm{C}$ in a shaking incubator and sampled for product formation every $24 \mathrm{~h}$ for five days, with net product formation equal to the product concentration at the timepoint of sampling, minus the product concentration at time zero. To serve as a control $(n=1)$, a bottle with $75 \%(\mathrm{v} / \mathrm{v})$ water instead of supernatant was included for each experimental condition totaling three individual 
controls for cellulose with water and three for cellobiose with water.

\section{Monoculture fermentations with substrate and biocatalyst additions}

Bioreactor fermentations at $80 \mathrm{~g} / \mathrm{L}$ corn stover were prepared in the same manner described above. During growth phase, determined to be approximately $t=48 \mathrm{~h}$ by monitoring gas production, respective solutions were added to the fermentations. Based on prior experiments, $60 \mathrm{ml}$ cellulose $(n=2)$ and cellobiose $(n=2)$ solutions were added at a concentration that effectively doubled the observed amount of glucan solubilized $(5.524 \mathrm{~g})$ in an uninterrupted $80 \mathrm{~g} / \mathrm{L}$ corn stover fermentation. Biocatalyst was obtained by culturing $C$. thermocellum LL1004 on MTC containing $25 \mathrm{~g} / \mathrm{L}$ cellobiose in a 1.2-L Sartorius bioreactor with a $1.0 \mathrm{~L}$ working volume. The fermentation broth was anaerobically and aseptically transferred out of the bioreactor during mid-growth phase $(t=24 \mathrm{~h})$ by a peristaltic pump, and further processed in an anaerobic glovebag (Coy Laboratory Products, Grass Lakes, MI). The broth was aseptically transferred into centrifuge bottles and the cell mass pelleted at $16,000 \times \mathrm{g}$ for $5 \mathrm{~min}$. The cell pellet was anaerobically resuspended in $200 \mathrm{~mL}$ (water), and $60 \mathrm{~mL}$ was immediately added to each bioreactor via syringe $(n=2)$. As a control, $60 \mathrm{ml}$ of anaerobic and autoclaved MilliQ water was added at the same timepoint $(t=48 \mathrm{~h})$ to an otherwise unaltered $80 \mathrm{~g} / \mathrm{L}$ corn stover fermentations $(n=2)$. Bioreactors proceeded until $t=168 \mathrm{~h}$, where they are harvested as described above.

\section{Coculture batch fermentations with low and high solids loadings}

Two additional media solutions were added to support coculture batch fermentations of $C$. thermocellum and T. thermosaccharolyticum. First, a $2 \%(\mathrm{v} / \mathrm{v})$ ammonium chloride $\left(\mathrm{NH}_{4} \mathrm{Cl}\right)$ solution was added with a bioreactor concentration of $2 \mathrm{~g} / \mathrm{L}$. Second, a $4 \%(\mathrm{v} / \mathrm{v})$ vitamin solution was added with bioreactor concentrations of $0.004 \mathrm{~g} / \mathrm{L}$ thiamine and $0.004 \mathrm{~g} / \mathrm{L}$ thioctic acid. For experiments comparing monocultures and cocultures, these two additional solutions were also given to monocultures to ensure an identical media background. Additionally, a third solution of xylose-free CTFüD was added in place of $T$. thermosaccharolyticm inoculum $(4 \% \mathrm{v} / \mathrm{v})$ for monocultures. The xylose-free CTFüD is identical to the aforementioned CTFüD medium, except does not include the primary carbon substrate, D-xylose. This was done to control for the presence of yeast extract persisting in the T. thermosaccharolyticum inoculum in the coculture runs. Fractional utilization of solubilized carbohydrates was determined based on concentrations in the unfermented feedstock, fermented solids, and spent broth as determined by quantitative saccharification protocols. Fractional sugar utilization was calculated as one minus the mass of sugars found in the liquid phase ( $\left.m_{\text {sugar, liquid phase }}\right)$ over the theoretical mass of sugars that have been solubilized based on fermented and unfermented solids ( $\left.m_{\text {sugar, unfermented solids }}-m_{\text {sugar, fermented solids }}\right)$.

Fractional sugar utilization

$$
=1-\frac{m_{\text {sugar, liquid phase }}}{m_{\text {sugar, unfermented solids }}-m_{\text {sugar, fermented solids }}} .
$$

\section{Abbreviations}

CBP: Consolidated bioprocessing; C-CBP: Consolidated bioprocessing with cotreatment; FCS: Fractional carbohydrate solubilization; AD: Anaerobic digestion; Av: Avicel; CB: Cellobiose; QS: Quantitative saccharification; LQS: Liquid quantitative saccharification; CBI: Center for Bioenergy Innovation; MTC: Media for thermophilic Clostridia; PES: Polyethersulfone; MOPS: Morpholinopropane sulfonic acid; CAZymes: Carbohydrate-active enzymes.

\section{Supplementary Information}

The online version contains supplementary material available at https://doi. org/10.1186/s13068-022-02110-4.

Additional file 1: Table S1. Data from figure 1 and figure 2, fractional carbohydrate solubilization (FCS) and fermentation end product concentrations. Table S2. Molar product ratios for increasing solids. Table S3. Data from figure 2, residual solubilized carbohydrates. Table S4. Data from figure 3, fermentation end product ratios. Figure S5. Residual solubilized carbohydrates per addition. Figure S6. Fermentation products per addition. Figure $\mathbf{S 7}$. Xylose utilization by cocultures on defined medium. Table S8. Data from figure 5 and figure 7, fractional carbohydrates solubilization and fermentation end product and residual solubilized carbohydrate concentrations for corn stover fermentations. Table S9. Data from figure 5 and figure 8 , fractional carbohydrates solubilization and fermentation end product and residual solubilized carbohydrate concentrations for senescent switchgrass fermentations. Table S10. Data from Figure 1, 2, 5, 7 and 8 , estimated contributions towards reported acetate titers from either lignocellulose deconstruction or microbial fermentation product.

Acknowledgements

The authors want to acknowledge POET research Inc. and Ernst Conservation Seeds for providing feedstock materials.

Authors' contributions

MRK, EKH, and LRL conceived the initial study and designed experiments. MRK performed experiments and prepared data. EKH evaluated data and with MRK designed follow-up experiments. MRK, EKH, and LRL wrote the manuscript, and MRK and EKH prepared the submission.

\section{Funding}

This work was supported by the Center for Bioenergy Innovation, a US Department of Energy Bioenergy Research Center supported by the Office of Biological and Environmental Research in the DOE Office of Science.

Availability of data and materials

All data generated and reported during this study are included in the published article and its additional files. 


\section{Declarations}

Ethics approval and consent to participate

Not applicable.

\section{Consent for publication}

All authors have read the manuscript and consent for its publication.

\section{Competing interests}

$L R L$ is a shareholder in a start-up company focusing on cellulosic biofuel production and conversion. There are no other competing interests.

\section{Author details}

${ }^{1}$ Thayer School of Engineering, Dartmouth College, 14 Engineering Drive, Hanover, NH 03755, USA. ${ }^{2}$ The Center for Bioenergy Innovation, Oak Ridge National Laboratory, Oak Ridge, TN 37831, USA.

\section{Received: 1 October 2021 Accepted: 15 January 2022}

Published online: 05 February 2022

\section{References}

1. Himmel ME, Ding S-Y, Johnson DK, Adney WS, Nimlos MR, Brady JW, et al. Biomass recalcitrance: engineering plants and enzymes for biofuels production. Science. 2007;315:804-7.

2. Lynd LR, Liang X, Biddy MJ, Allee A, Cai H, Foust T, et al. Cellulosic ethanol: status and innovation. Vol. 45, Current opinion in biotechnology. Elsevier Ltd; 2017. p. 202-11.

3. Humbird D, Davis R, Tao L, Kinchin C, Hsu D, Aden A, et al. Process design and economics for biochemical conversion of lignocellulosic biomass to ethanol: dilute-acid pretreatment and enzymatic hydrolysis of corn stover. 2002.

4. Mosier N, Wyman C, Dale B, Elander R, Lee YY, Holtzapple M, et al. Features of promising technologies for pretreatment of lignocellulosic biomass. Biores Technol. 2005;96(6):673-86

5. Hu F, Ragauskas A. Pretreatment and lignocellulosic chemistry. Bioenergy Res. 2012;5:1043-66.

6. Lynd LR, Weimer PJ, van ZyI WH, Pretorius IS. Microbial cellulose utilization: fundamentals and biotechnology. Microbiol Mol Biol Rev. 2002;66(3):506-77.

7. Paye JMD, Guseva A, Hammer SK, Gjersing E, Davis MF, Davison BH, et al. Biological lignocellulose solubilization: comparative evaluation of biocatalysts and enhancement via cotreatment. Biotechnol Biofuels. 2016;9(1):1-13.

8. Balch ML, Holwerda EK, Davis MF, Sykes RW, Happs RM, Kumar R, et al. Lignocellulose fermentation and residual solids characterization for senescent switchgrass fermentation by: Clostridium thermocellum in the presence and absence of continuous in situ ball-milling. Energy Environ Sci. 2017:10(5):1252-61.

9. Holwerda EK, Worthen RS, Kothari N, Lasky RC, Davison BH, Fu C, et al. Multiple levers for overcoming the recalcitrance of lignocellulosic biomass. Biotechnol Biofuels. 2019;12(1):1-12.

10. Xu Q, Resch MG, Podkaminer K, Yang S, Baker JO, Donohoe BS, et al. Cell Biology: dramatic performance of Clostridium thermocellum explained by its wide range of cellulase modalities. Sci Adv. 2016;2(2):e1501254.

11. Izquierdo JA, Pattathil S, Guseva A, Hahn MG, Lynd LR. Comparative analysis of the ability of Clostridium clariflavum strains and Clostridium thermocellum to utilize hemicellulose and unpretreated plant material. Biotechnol Biofuels. 2014;7(1):1-18.

12. Xiong W, Reyes LH, Michener WE, Maness PC, Chou KJ. Engineering cellulolytic bacterium Clostridium thermocellum to co-ferment celluloseand hemicellulose-derived sugars simultaneously. Biotechnol Bioeng. 2018;115(7):1755-63.

13. Demain AL, Newcomb M, Wu JHD. Cellulase, Clostridia, and ethanol. Microbiol Mol Biol Rev. 2005;69(1):124-54

14. Zhang J, Tang M, Viikari L. Xylans inhibit enzymatic hydrolysis of lignocelIulosic materials by cellulases. Biores Technol. 2012;121:8-12.

15. Zhai R, Hu J, Saddler JN. The inhibition of hemicellulosic sugars on cellulose hydrolysis are highly dependant on the cellulase productive binding, processivity, and substrate surface charges. Biores Technol. 2018;1(258):79-87.

16. Qing Q, Yang B, Wyman CE. Xylooligomers are strong inhibitors of cellulose hydrolysis by enzymes. Biores Technol. 2010;101(24):9624-30.

17. Xue S, Uppugundla N, Bowman MJ, Cavalier D, da Costa Sousa L, Dale BE, et al. Sugar loss and enzyme inhibition due to oligosaccharide accumulation during high solids-loading enzymatic hydrolysis. Biotechnol Biofuels. 2015;8(1):1-14

18. Verbeke TJ, Giannone RJ, Klingeman DM, Engle NL, RydzakT, Guss AM, et al. Pentose sugars inhibit metabolism and increase expression of an AgrD-type cyclic pentapeptide in Clostridium thermocellum. Sci Rep. 2017;23:7.

19. Shao X, Murphy SJ, Lynd LR. Characterization of reduced carbohydrate solubilization during Clostridium thermocellum fermentation with high switchgrass concentrations. Biomass Bioenerg. 2020;1:139.

20. Beri D, Herring CD, Blahova S, Poudel S, Giannone RJ, Hettich RL, et al. Coculture with hemicellulose-fermenting microbes reverses inhibition of corn fiber solubilization by Clostridium thermocellum at elevated solids loadings. Biotechnol Biofuels. 2021;14(1):1-13.

21. Levin DB, Verbeke TJ, Munir R, Islam R, Ramachandran U, Lal S, et al. Omics approaches for designing biofuel producing cocultures for enhanced microbial conversion of lignocellulosic substrates. In: Direct microbial conversion of biomass to advanced biofuels. Elsevier; 2015. p. 335-63.

22. Ng TK, Ben-Bassat A, Zeikus JG. Ethanol production by thermophilic bacteria: fermentation of cellulosic substrates by cocultures of Clostridium thermocellum and Clostridium thermohydrosulfuricum. Appl Environ Microbiol. 1981:41(6):1337-43.

23. Saddler JN, Chan MKH. Conversion of pretreated lignocellulosic substrates to ethanol by Clostridium thermocellum in mono- and co-culture with Clostridium thermosaccharolyticum and Clostridium thermohydrosulphuricurn. Can J Microbiol. 1984:30:212-20.

24. Liu Y, Yu P, Song X, Qu Y. Hydrogen production from cellulose by coculture of Clostridium thermocellum JN4 and Thermoanaerobacterium thermosaccharolyticum GD17. Int J Hydrogen Energy. 2008;33(12):2927-33.

25. He Q, Hemme CL, Jiang H, He Z, Zhou J. Mechanisms of enhanced cellulosic bioethanol fermentation by co-cultivation of Clostridium and Thermoanaerobacter spp. Biores Technol. 2011;102(20):9586-92.

26. Wang F, Wang M, Zhao Q, Niu K, Liu S, He D, et al. Exploring the relationship between Clostridium thermocellum JN4 and Thermoanaerobacterium thermosaccharolyticum GD17. Front Microbiol. 2019;10:10.

27. Froese A, Schellenberg J, Sparling R. Enhanced depolymerization and utilization of raw lignocellulosic material by co-cultures of Ruminiclostridium thermocellum with hemicellulose-utilizing partners. Can J Microbiol. 2019;65(4):296-307.

28. Beri D, York WS, Lynd LR, Peña MJ, Herring CD. Development of a thermophilic coculture for corn fiber conversion to ethanol. Nat Commun. 2020;11(1):1-11.

29. Kristensen JB, Felby C, Jørgensen $H$. Yield-determining factors in high-solids enzymatic hydrolysis of lignocellulose. Biotechnol Biofuels. 2009;8:2.

30. Weiss ND, Felby C, Thygesen LG. Enzymatic hydrolysis is limited by biomass-water interactions at high-solids: improved performance through substrate modifications. Biotechnol Biofuels. 2019;12(1):1-13.

31. Jørgensen $\mathrm{H}$, Vibe-Pedersen J, Larsen J, Felby C. Liquefaction of lignocellulose at high-solids concentrations. Biotechnol Bioeng. 2007:96(5):862-70.

32. Mohagheghi A, Tucker M, Grohmann K, Wyman C. High solids simultaneous saccharification and fermentation of pretreated wheat straw to ethanol. Appl Biochem Biotechnol. 1992;67:81.

33. Hodge DB, Karim MN, Schell DJ, McMillan JD. Soluble and insoluble solids contributions to high-solids enzymatic hydrolysis of lignocellulose. Biores Technol. 2008;99(18):8940-8.

34. Holtzapple M, Cognata M, Shu Y, Hendrickson C. Inhibition of Trichoderma reesei celiulase by sugars and solvents. Biotechnol Bioeng. 1990:36:275-87.

35. Jing $X$, Zhang $X$, Bao J. Inhibition performance of lignocellulose degradation products on industrial cellulase enzymes during cellulose hydrolysis. Appl Biochem Biotechnol. 2009;159(3):696-707.

36. Andrić P, Meyer AS, Jensen PA, Dam-Johansen K. Reactor design for minimizing product inhibition during enzymatic lignocellulose hydrolysis: I. Significance and mechanism of cellobiose and glucose inhibition on cellulolytic enzymes. Biotechnol Adv. 2010;28:308-24. 
37. Malgas S, Kwanya Minghe VM, Pletschke BI. The effect of hemicellulose on the binding and activity of cellobiohydrolase I, Cel7A, from Trichoderma reesei to cellulose. Cellulose. 2020;27(2):781-97.

38. Qing Q, Wyman CE. Supplementation with xylanase and $\beta$-xylosidase to reduce xylo-oligomer and xylan inhibition of enzymatic hydrolysis of cellulose and pretreated corn stover. Biotechnol Biofuels. 2011;4(1):18

39. Selig MJ, Knoshaug EP, Adney WS, Himmel ME, Decker SR. Synergistic enhancement of cellobiohydrolase performance on pretreated corn stover by addition of xylanase and esterase activities. Biores Technol. 2008;99(11):4997-5005.

40. Öhgren K, Bura R, Saddler J, Zacchi G. Effect of hemicellulose and lignin removal on enzymatic hydrolysis of steam pretreated corn stover. Biores Technol. 2007;98(13):2503-10.

41. Berlin A, Balakshin M, Gilkes N, Kadla J, Maximenko V, Kubo S, et al. Inhibition of cellulase, xylanase and $\beta$-glucosidase activities by softwood lignin preparations. J Biotechnol. 2006;125(2):198-209.

42. Rajan K, Carrier DJ. Effect of dilute acid pretreatment conditions and washing on the production of inhibitors and on recovery of sugars during wheat straw enzymatic hydrolysis. Biomass Bioenerg. 2014;62:222-7.

43. Wu G, Healy MG, Zhan X. Effect of the solid content on anaerobic digestion of meat and bone meal. Biores Technol. 2009;100(19):4326-31.

44. Chen X, Yan W, Sheng K, Sanati M. Comparison of high-solids to liquid anaerobic co-digestion of food waste and green waste. Biores Technol. 2014:154:215-21.

45. Abbassi-Guendouz A, Brockmann D, Trably E, Dumas C, Delgenès JP, Steyer JP, et al. Total solids content drives high solid anaerobic digestion via mass transfer limitation. Biores Technol. 2012;111:55-61.

46. Wang Z, Jiang $Y$, Wang S, Zhang Y, Hu Y, Hu Z, et al. Impact of total solids content on anaerobic co-digestion of pig manure and food waste: Insights into shifting of the methanogenic pathway. Waste Manag. 2020;114:96-106.

47. Forster-Carneiro T, Pérez M, Romero LI. Influence of total solid and inoculum contents on performance of anaerobic reactors treating food waste. Biores Technol. 2008;99(15):6994-7002.

48. Fernández J, Pérez M, Romero LI. Effect of substrate concentration on dry mesophilic anaerobic digestion of organic fraction of municipal solid waste (OFMSW). Biores Technol. 2008;99(14):6075-80

49. Holwerda EK, Olson DG, Ruppertsberger NM, Stevenson DM, Murphy SJL, Maloney MI, et al. Metabolic and evolutionary responses of Clostridium thermocellum to genetic interventions aimed at improving ethanol production. Biotechnol Biofuels. 2020;13(1):1-20.

50. Holwerda EK, Thorne PG, Olson DG, Amador-Noguez D, Engle NL, Tschaplinski TJ, et al. The exometabolome of Clostridium thermocellum reveals overflow metabolism at high cellulose loading. Biotechnol Biofuels. 2014;7(1):1-11.

51. Argyros DA, Tripathi SA, Barrett TF, Rogers SR, Feinberg LF, Olson DG, et al. High ethanol Titers from cellulose by using metabolically engineered thermophilic, anaerobic microbes. Appl Environ Microbiol. 2011;77(23):8288-94.

52. Verbeke TJ, Garcia GM, Elkins JG. The effect of switchgrass loadings on feedstock solubilization and biofuel production by Clostridium thermocellum. Biotechnol Biofuels. 2017;10(1):1-9.

53. Basen M, Rhaesa AM, Kataeva I, Prybol CJ, Scott IM, Poole FL, et al. Degradation of high loads of crystalline cellulose and of unpretreated plant biomass by the thermophilic bacterium Caldicellulosiruptor bescii. Biores Technol. 2014;152:384-92.

54. Straub CT, Khatibi PA, Otten JK, Adams MWW, Kelly RM. Lignocellulose solubilization and conversion by extremely thermophilic Caldicellulosiruptor bescii improves by maintaining metabolic activity. Biotechnol Bioeng. 2019;116(8):1901-8.

55. Wyman CE, Balan V, Dale BE, Elander RT, Falls M, Hames B, et al. Comparative data on effects of leading pretreatments and enzyme loadings and formulations on sugar yields from different switchgrass sources. Biores Technol. 2011;102(24):11052-62.

56. Kumar R, Mago G, Balan V, Wyman CE. Physical and chemical characterizations of corn stover and poplar solids resulting from leading pretreatment technologies. Biores Technol. 2009;100(17):3948-62.

57. Zhang Y-HP, Lynd LR. Cellulose utilization by Clostridium thermocellum: bioenergetics and hydrolysis product assimilation. Proc Natl Acad Sci. 2005;102(20):7321-5.
58. Shi J, Ebrik MA, Yang B, Garlock RJ, Balan V, Dale BE, et al. Application of cellulase and hemicellulase to pure xylan, pure cellulose, and switchgrass solids from leading pretreatments. Biores Technol. 2011;102(24):11080-8.

59. Gu J, Catchmark JM. The impact of cellulose structure on binding interactions with hemicellulose and pectin. Cellulose. 2013:20(4):1613-27.

60. Köhnke T, Östlund $\AA$, Brelid H. Adsorption of arabinoxylan on cellulosic surfaces: influence of degree of substitution and substitution pattern on adsorption characteristics. Biomacromol. 2011;12(7):2633-41.

61. Wang X, Li K, Yang M, Zhang J. Hydrolyzability of xylan after adsorption on cellulose: exploration of xylan limitation on enzymatic hydrolysis of cellulose. Carbohyd Polym. 2016;5(148):362-70.

62. Sluiter A, Hames B, Ruiz R, Scarlata C, Sluiter J, Templeton D, et al. Determination of structural carbohydrates and lignin in biomass: laboratory analytical procedure (LAP) (Revised July 2011). 2008.

63. Sluiter A, Hames B, Ruiz R, Scarlata C, Sluiter J, Templeton D. Determination of ash in biomass: laboratory analytical procedure (LAP); Issue Date: 7/17/2005. 2008

64. Holwerda EK, Hirst KD, Lynd LR. A defined growth medium with very low background carbon for culturing Clostridium thermocellum. J Ind Microbiol Biotechnol. 2012;39(6):943-7.

65. Olson DG, Lynd LR. Transformation of Clostridium thermocellum by electroporation. In: Methods in enzymology. Academic Press Inc.; 2012. p. 317-30.

\section{Publisher's Note}

Springer Nature remains neutral with regard to jurisdictional claims in published maps and institutional affiliations.
Ready to submit your research? Choose BMC and benefit from:

- fast, convenient online submission

- thorough peer review by experienced researchers in your field

- rapid publication on acceptance

- support for research data, including large and complex data types

- gold Open Access which fosters wider collaboration and increased citations

- maximum visibility for your research: over 100M website views per year

At BMC, research is always in progress.

Learn more biomedcentral.com/submissions 